\title{
Design a New Configuration of Micro Strip Rectangle Patch Antenna on Different Thickness Substrate for Telemedicine Applications
}

\author{
Parisa Shirvani*, Hamidreza Shirzadfar ${ }^{\dagger}$ \\ Department of Biomedical Engineering, Sepahan Institute of Higher Education, Isfahan, 81799-13895, Iran
}

(Received 23 June 2016; published online 03 October 2016)

\begin{abstract}
Today, the telecommunication and IT technology widely have been used in medical and related sciences. Communication sciences provide an ability in medical service to the centers where that geographically isolated from each other. Hence, telecommunication antennas have significant role in sending telemedicine's information at real-time. In this paper an initiated antenna for development of patch antenna characteristics has been discussed and analyzed. More over different thickness of dielectric substrate was used and the effect of it such as bandwidth, gain, return loss and Voltage Standing Wave Ratio (VSWR) have been compared and showed in the table. The proposed antenna operates at $2.45 \mathrm{GHz}$ for telemedicine applications. The simulation process has been done through High Frequency Structure Simulator (HFSS).
\end{abstract}

Keywords: Telemedicine, Rectangle patch antenna, Gain, Micro strip antenna, $S$ parameters.

DOI: 10.21272/jnep.8(3).03028

PACS numbers: 84.40.Ba, 84.40.Ua

\section{INTRODUCTION}

The term "telemedicine" is combination of two words: Tele and Medicine, tele is a prefix for distant and medicine means treat and health. So, telemedicine describes the medical services over distance [1]. Telecommunications used in sending medical information between a pair of transmitters and receivers in medical applications [2].

Telemedicine is a medical practice remotely using information and communications technology. It allows online doctor-patient relationship and dialogue between health professional in an exchange of sound, images and data worldwide.

Telemedicine is not only medicine in distance, but also this is a new approach to doctor-patient relationship and the singular colloquium.

The history of telemedicine starts in the $60 \mathrm{~s}$ the United States, including the networking of teleconsultation and tele education programs. Two other important dates can also serve as the emergence of telemedicine: first it was in 1965 the primary video conference in cardiac surgery between the United States and Switzerland, in 1973 the first international conference on telemedicine, which is done several projects [3].

Thanks to satellite links, telemedicine will develop in the late 1970s through the educated research programs by organizations and agencies that are itself directly confronted the problem of access to care for people located in inaccessible places or difficult to access. For example, NASA will develop telemedicine programs for its astronauts and the US military of telecare systems to deliver first aid to the wounded on the battlefields of Vietnam Stations of study and research in Antarctica as well as oilfield stations in the oceans will consider the development of applied telemedicine. Finally the US Navy will develop experimental telemedicine programs [4].

Since the mid-90s the telemedicine penetrates more

\footnotetext{
*shirvani.parisa@sepahan.ac.ir
}

$\dagger$ h.shirzadfar@sepahan.ac.ir and more in clinical specialist. Allen and Grigsby have recorded nearly 40000 tele-consultations in 1988 in more than 33 specialties [5]. Tele-radiology with over 250000 consultation just in 1997, remains the main application of telemedicine in European Union (EU) [6]. Since 1994, the world has experienced phenomenal emergence of interest in the internet, not only as a source of information or tele-education, but also as means of communication.

If the desires to promote the access of rural populations to quality care to improve the management of emergency has been engine-out and it's always partly interest and current motivations. The recent development of telemedicine programs is part of a more comprehensive approach to reorganization of the health system and health care provision [7].

The proposed frequency in telemedicine applications is $2.45 \mathrm{GHz}$ that is including in UHF band. The reasons to use this range of frequency in telemedicine are:

1- This band is free of charge.

2- There is no frequency interference at $2.45 \mathrm{GHz}$.

3- This frequency uses for the Wi-Fi telecommunication.

The different frequency bands of telecommunications are presented in Fig. 1.

In this paper we have demonstrated the novel schematic of micro strip rectangle patch antenna which proposed in biomedical domain particularly in telemedicine. The simulation by High Frequency Structure Simulator (HFSS) has been done. The advantages of proposed antenna are high gain which is acceptable in biomedical frequency $(2.45 \mathrm{GHz})$ and also we have achieved reasonable $S$-parameters.

\section{MATHEMATICAL ANALYSIS OF MI- CROSTRIP PATCH ANTENNA}

A micro strip rectangle patch antenna (MRPA) consists of two parallel conducting layers separated by a 


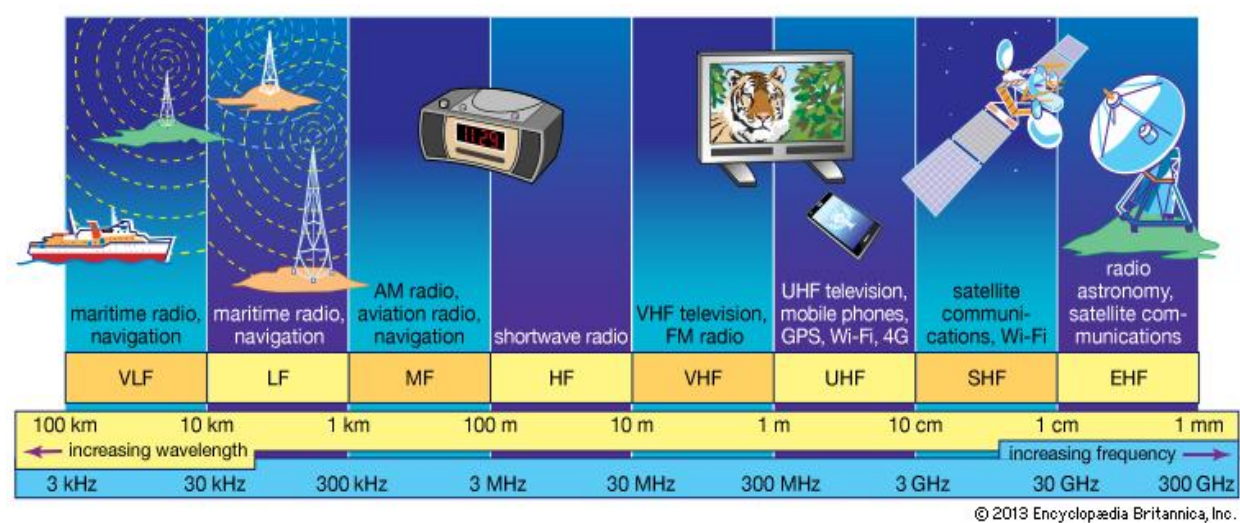

Fig. 1 - The frequency bands of telecommunication [8]

single dielectric substrate in the most basic form. The upper conducting layer names Patch and operates as a radiator as shown in Fig. 2. Length and width of the conductor patch should be calculated. The lower conducting layer operates as a ground plane [9].

Micro strip patch antenna design needs to know the following parameters: dielectric constant $\left(\varepsilon_{r}\right)$, resonant frequency $\left(f_{r}\right)$ and height of the substrate $(h)$. With using these parameters we can calculate dimensions of the patch [10]. The dielectric constant are usually in the range of $\left(2.2 \leq \varepsilon_{r} \leq 12\right)[11,12]$.
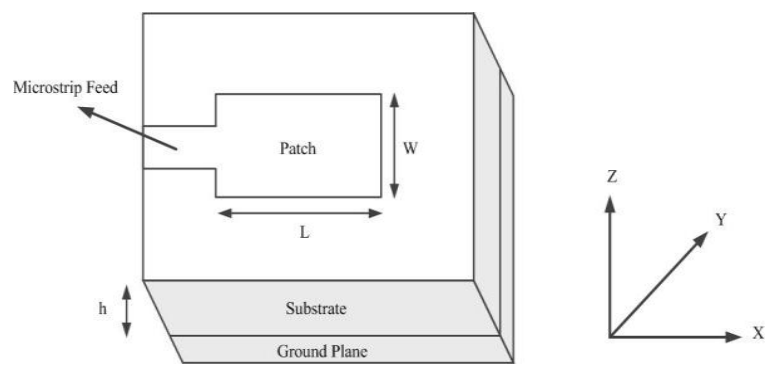

Fig. 2 - Schematic of micro strip patch antenna.

The equation for the width of the patch [12]:

$$
w=\frac{c}{2 f_{0} \sqrt{\frac{\varepsilon_{r}+1}{2}}}
$$

Where $c$ is free space velocity of light [12].

$$
\frac{w}{h}>1
$$

The effective dielectric constant has values in the range of $1<\varepsilon_{r e f f}<\mathcal{E}$. Effective dielectric constant of antenna is [13]:

$$
\varepsilon_{\text {eff }}=\frac{\varepsilon_{r}+1}{2}+\frac{\varepsilon_{r}-1}{2} \sqrt{\frac{1}{1+12 \frac{h}{w}}}
$$

Effective dielectric length of antenna calculated by:

$$
l_{\text {eff }}=\frac{c}{2 f_{r} \sqrt{\varepsilon_{\text {eff }}}}
$$

Equation for the difference in the length [14]:

$$
\Delta l=0.412 h \frac{\left(\varepsilon_{\text {eff }}+0.3\right)\left(\frac{w}{h}+0.264\right)}{\left(\varepsilon_{\text {eff }}-0.258\right)\left(\frac{w}{h}+0.813\right)}
$$

The length is:

$$
l=l_{\text {eff }}-2 \Delta l
$$

\section{DESIGN MRPA}

As telemedicine applications work at $2.45 \mathrm{GHz}$ for Wi-Fi communication, so we designed our antenna at this frequency. For this design we use of $\varepsilon_{r}=2.17$ and loss tangent is $\delta=0.002$.Proposed antenna was simulated in three different thickness of dielectric substrate $3.175 \mathrm{~mm}, 4 \mathrm{~mm}$ and $4.808 \mathrm{~mm}$ and the results were compared. To achieve a good performance antenna, thickness dielectric substrate with a low dielectric constant is needed which provides good efficiency and bandwidth.

There are three models for the analysis of micro strip patch antenna: 1 - the transmission line model [15] 2 cavity model [16] 3 - full wave model [17]. For designing our antenna, the simplest model means the transmission line model was used. This model has two conducting layer patch and ground plane. Electric field lines that are between patch and ground plane. Most of the electric field lines through the dielectric substrate crossing and some part in the air.

Fig. 3 presents the structure of antenna. Dimensions of patch antenna are shown in Table 1. The length $L$ and width $W$ of the patch micro strip antenna are given by $L=39.72, W=48.63 \mathrm{~mm}$.

Patch antenna surrounded by an air box boundary and virtual radiation to create far field radiation pattern.

\section{SIMULATION RESULTS}

The proposed antenna simulation has done with HFSS software. The measured parameters were gain, bandwidth, s parameters and VSWR. Results have been obtained for different thicknesses substrate $3.175 \mathrm{~mm}$, $4 \mathrm{~mm}$ and $4.808 \mathrm{~mm}$ and are shown ordered by their thickness (see Table 2). As observed in Fig. 4, we 


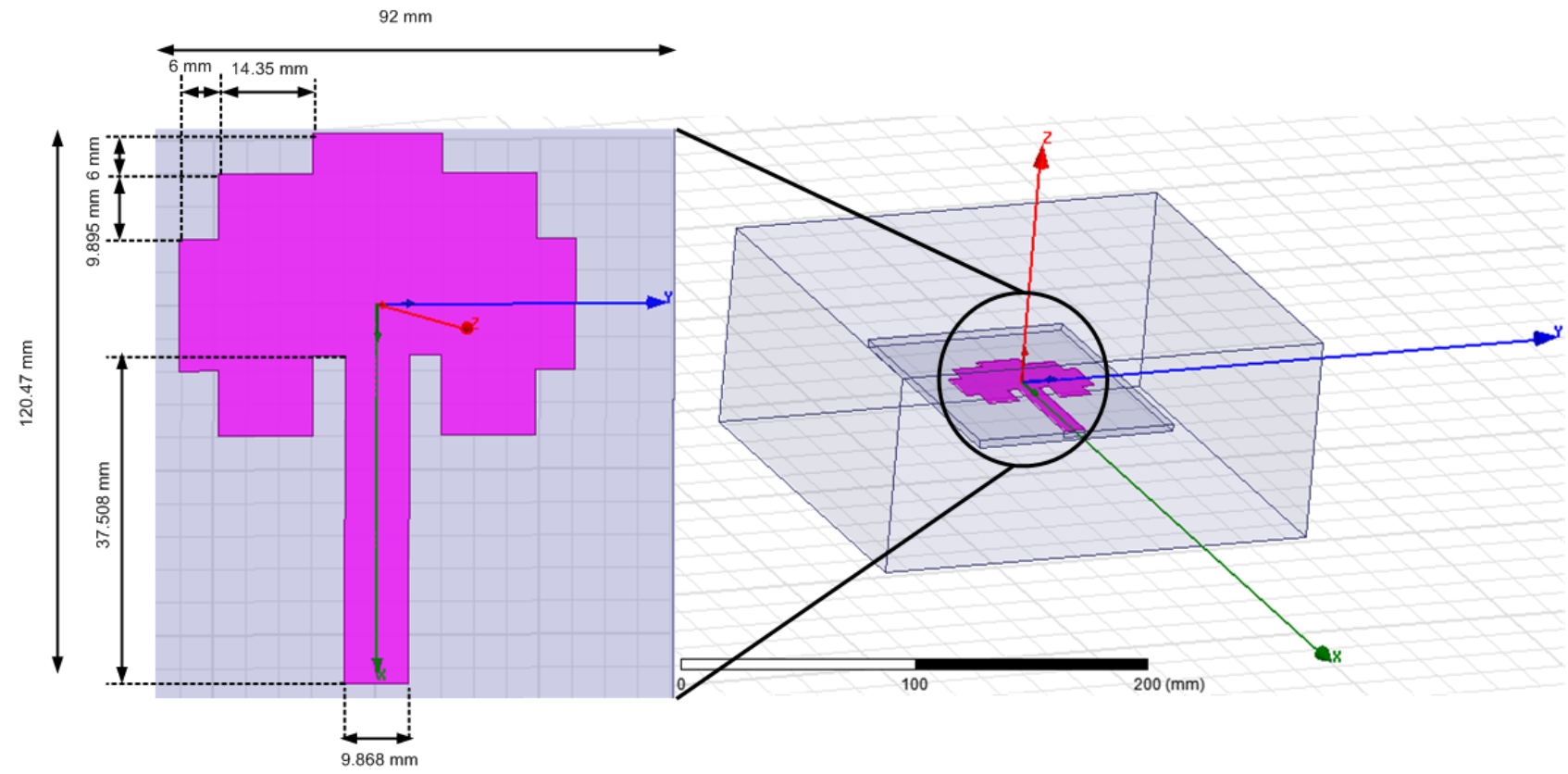

Fig. 3 - Structure of MRPA antenna
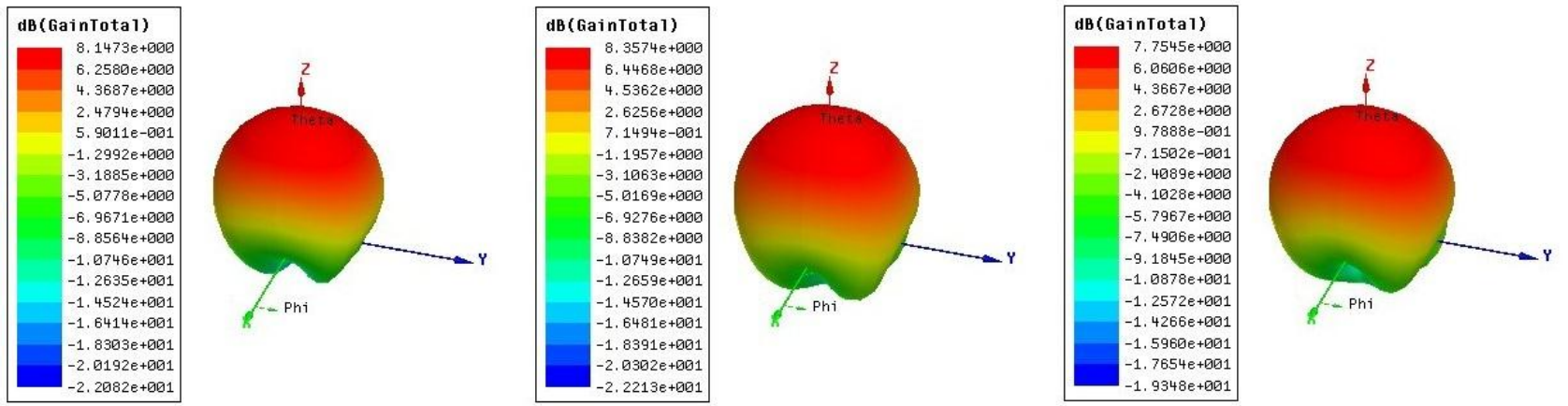

$\mathrm{b}$

c

Fig. 4-The 3D polar plot of rectangle micro strip patch antenna; substrate thickness $H_{1}=3.175 \mathrm{~mm}$ (a), $H_{2}=4 \mathrm{~mm} \mathrm{(b),} H_{3}=4.808 \mathrm{~mm}$ (c)

Table 1 - Dimensions of patch antenna.

\begin{tabular}{|l|l|}
\hline$L=$ patch dimension of $\mathrm{x}$ & $39.72 \mathrm{~mm}$ \\
\hline$W=$ patch dimension of $\mathrm{y}$ & $48.63 \mathrm{~mm}$ \\
\hline$X$ substrate dimension & $120.47 \mathrm{~mm}$ \\
\hline$Y$ substrate dimension & $92 \mathrm{~mm}$ \\
\hline$X$ feed dimension & $37.508 \mathrm{~mm}$ \\
\hline$Y$ feed dimension & $9.868 \mathrm{~mm}$ \\
\hline
\end{tabular}

Table 2 - Results of simulation.

\begin{tabular}{|l|l|l|l|}
\hline Substrate thickness & Gain & Bandwidth & VSWR \\
\hline$H_{1}=3.175 \mathrm{~mm}$ & $8.1473 \mathrm{~dB}$ & $100 \mathrm{MHz}$ & $1.2($ at $2.3 \mathrm{GHz})$ \\
\hline$H_{2}=4 \mathrm{~mm}$ & $8.3574 \mathrm{~dB}$ & $100 \mathrm{MHz}$ & $1.3($ at $2.3 \mathrm{GHz})$ \\
\hline$H_{3}=4.808 \mathrm{~mm}$ & $7.7545 \mathrm{~dB}$ & $140 \mathrm{MHz}$ & $1.2($ at $2.2 \mathrm{GHz})$ \\
\hline
\end{tabular}




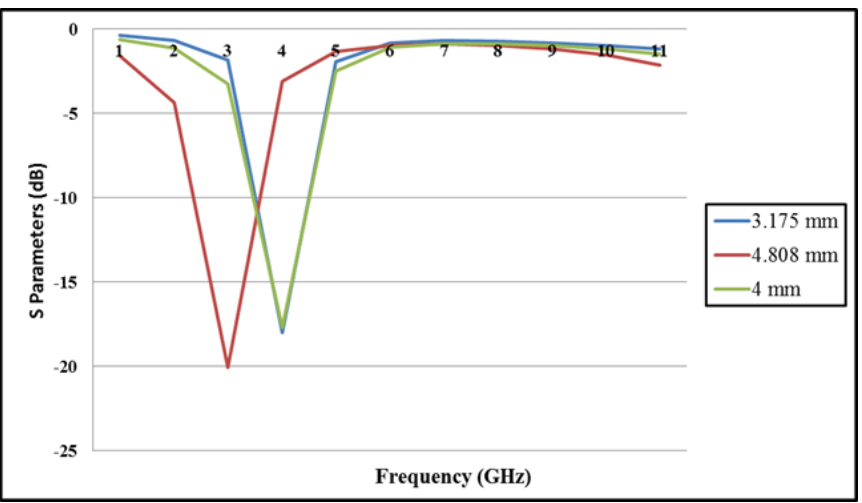

Fig 5-The comparison results between $\mathrm{S}$ parameters and bandwidths

have obtained the different gains of MPRA for several thicknesses substrate. The best gain's result achieved at thickness of $4 \mathrm{~mm}$ and its gain approximately is 8.36 dB. Furthermore, the results are shown that antenna with $4.808 \mathrm{~mm}$ thickness has a more bandwidth and equal to $140 \mathrm{MHz}$

As demonstrated in Fig. 5, the $S$ parameters or return loss less than of $-10 \mathrm{~dB}$ is reasonably acceptable for determining bandwidth.

The best results of $S$ parameters are found for patch antenna with $4.808 \mathrm{~mm}$ thickness.

Additionally, the results of VSWR are displayed in Table 2 and Fig. 6. All of the amounts are between 1 and $2 \mathrm{~dB}$. VSWR means as the ration maximum to minimum voltage which is measured by HFSS software and compared between three substrate thickness $H_{1}=3.175 \mathrm{~mm}, H_{2}=4 \mathrm{~mm}$ and $H_{3}=4.808 \mathrm{~mm}$. There are some variations around resonance frequency.

\section{REFERENCES}

1. B. Fong, A.C.M. Fong, C.K. Li, Telemedicine technologies: Information technologies in medicine and telehealth (John Wiley \& Sons: 2011).

2. C. Pattichis, E. Kyriacou, S. Voskaride, M. Pattichis, R. Istepanian, C.N. Schizas, IEEE 44, 143 (2002).

3. C. Hoving, A. Visser, P.D. Mullen, B. van den Borne, Patient Educ. Couns. 78, 275 (2010).

4. E.W. Ferguson, C.R. Doarn, J.C. Scott, J. Med. Syst. 19, 35 (1995)

5. A. Allen, B. Grigsby, Telemedicine today 6, 18 (1998).

6. R. Wootton, J. Craig, V. Patterson, Introduction to telemedicine (Royal Society of Medicine Press: 2006).

7. A.K. Jha, J.B. Perlin, K.W. Kizer, R.A. Dudley, New Engl. J. Med. 348, 2218 (2003).

8. http://www.britannica.com/topic/telecommunication s-media.

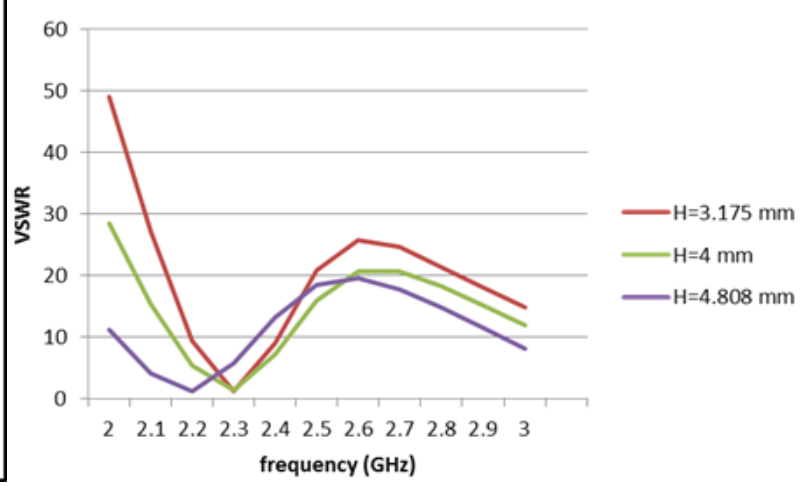

Fig. 6 - The voltage standing wave ratio (VSWR) results for substrate thickness $H_{1}=3.175 \mathrm{~mm}, H_{2}=4 \mathrm{~mm}, H_{3}=4.808 \mathrm{~mm}$

\section{CONCLUSION}

A micro strip antenna has been studied. The novel micro strip rectangle patch antenna is created and simulated by HFSS software. The operated frequency is selected $2.45 \mathrm{GHz}$ as explained in above.

The different thickness substrate is analyzed (3.175 $\mathrm{mm}, 4 \mathrm{~mm}$ and $4.808 \mathrm{~mm}$ ). Moreover, the results are shown that the offered patch antenna has high gain approach $8 \mathrm{~dB}$ that is better gain got for $4 \mathrm{~mm}$ thickness substrate. Also, thickness $4.808 \mathrm{~mm}$ has more bandwidth comparing other thicknesses. Finally, the antenna with thickness $4.808 \mathrm{~mm}$ reached perfect return loss. Furthermore, VSWR for all of thicknesses is less than 2 that is acceptable result.

By using metamaterials is possible to increase the bandwidth of proposed antenna. The meta-substrate behaves like an inhomogeneous magnetic substrate. In our future work we will plan to enhance bandwidth of antenna which is more usable in telemedicine domain.

9. D.M. Pozar, D.H. Schaubert, John Wiley \& Sons (1995).

10. D.M. Pozar, Proc. IEEE 80, 79 (1992).

11. T. Huynh, K.-F. Lee, Electron. Lett. 31, 1310 (1995).

12. C.A. Balanis, Antenna theory: analysis and design (John Wiley \& Sons: 2016).

13. L.I. Basilio, M.A. Khayat, J.T. Williams, S.A. Long, IEEE T. Antenn. Propag. 49, 45 (2001)

14. J. James, P. Hall, Peter Peregrinus Ltd, London on behalf of the IEE, 1 (1989).

15. K. Odeyemi, D. Akande, E. Ogunti, Design of an S-Band Rectangular Microstrip Patch Antenna, Eur. J. Sci. Res. 55, 72 (2011).

16. S. Park, C. Kim, Y. Jung, H. Lee, D. Cho, M. Lee, AEUInt. J. Electron. Comm. 64, 607 (2010).

17. S.R. Bhongale, P.N. Vasambekar, Square Shaped Microstrip Patch Antenna at $2.45 \mathrm{GHz}$. 